\title{
La historia de la filosofía como problema filosófico
}

\author{
MIGUEL CANDEL \\ Universidad de Barcelona
}

\section{¿La filosofía como historia o la historia como filosofía?}

En el siglo xviri la verdad cesó de considerarse eterna y su persecución pasó a tener sentido como tal: como movimiento en pos de un objeto también móvil. Vico, Herder, Hegel, Marx, Comte marcan una época en la que el viejo término griego historía deja de denotar una mera descripción de objetos para convertirse en interpretación de acontecimientos.

Desde entonces, no sorprende que muchos filósofos, cuando no cientificos positivos, traten de identificar el saber con la historia del saber. Pero en filosofía no hay tautologías perfectas. Historia y filosofía no son términos con los que pueda construirse una ecuación: para bien o para mal (o para ambas cosas), el filosofo, a diferencia del matemático, suele interpretar el signo ' $=$ ' no como 'identidad con' sino como 'reducción a'; y aquí no cabe la propiedad commutativa. Por eso hay que preguntarse si lo que el historicismo filosófico representa es una reducción del primer término al segundo o viçeversa.

Desdichadamente es fácil encerrarse en el siguiente dilema: o bien leemos las tilosofías del pasado en forma tal que ellas se tornen relevantes para nuestros problemas y nuestras empresas contemporáneas, transformándolas, en la medida de lo posible, en lo que ellas habrian sido en caso de formar parte de la filosofía actual [...]; o bien, en lugar de ello, nos tomamos gran cuidado en leerlas en sus propios términos, preservan- do meticulosamente su carácter idiosincrático y específico, de modo tal que no puedan aparecer en el presente sino como un conjunto de piezas de museo. ${ }^{1}$

Dicho con otras palabras, la historicidad de la filosofía suele entenderse, según la querencia o el lastre escolastico de cada uno, de una de estas dos maneras antitéticas e irreconciliables:

a) Como doxografía preliminar al tratamiento actual de los problemas, al modo como la Escolástica medieval y moderna introducia la discusión de una tesis con el recordatorio de las opiniones de los clásicos. Es el enfoque que reduce la filosofía no actual a historia.

b) Como recreación del pensamiento anterior dentro de las catcgorias del contemporáneo; procedimiento que, como señala Foucault (Les mots et les choses), es el característico del género "comentario", propio a su vez de la exégesis premoderna, insensible al anacronismo. Es el enfoque que reduce la historia a filosofía actual.

Rodolfo Mondolfo, uno de los más grandes historiadores de la filosofía de este siglo, ofrece una postura de aparente síntesis cuando afirma, siguiendo a Vico, que sla naturaleza de una cosa la da su nacimiento" y que, por tanto, los problemas filosóficos sólo pueden penetrarse adecuadamente por una visión que los enfoque a partir de sus orígenes históricos. El hecho de que la especulación filosófica de cada época, cualquiera que sea su orientación (dogmática, crítica o escéptica), aspire en definitiva a una elucidación de su 
objeto sub specie aetemi no solo no es incompatible con un planteamiento genético (sub specie temporis) de ese mismo objeto, sino que la consideracion histórica se hace imprescindible para purificar la propia reflexion, hic et nunc, de aquellos condicionamientos contingentes, históricos, que scontaminany su presunta pureza intemporal: quien, como Descartes, pretenda haber hecho borrón y cuenta nueva de la filosofía anterior, deberá esperar que un Gilson publique su Index scholasticocartésien particular en el que se pongan en evidencia las insospechadas deudas contraídas con el pasado. ${ }^{2}$

Podemos suscribir provisionalmente este planteamiento. Pero a condición de añadir la siguiente distinción:

Según Mondolfo, parece claro que no se puede hacer filosofia hoy sin ajustar cuentas con el ayer, sin una visión diacrónica de los problemas (o falsos problemas) en tomo a los que gravita cada constelación sincrónica de ideas. En otras palabras, si el fin perseguido por la actividad intelectual es de naturaleza filosófica, el medio para alcanzarlo no puede ser sino historiográfico. (Quizá podría decirse incluso, con MacIntyre, que el ejercicio de la filosofía requiere una patente que sólo Platón está autorizado a expedir, como "inventor" del género filosófico, lo que harra consustancial a dicho ejercicio la retrospección histórica; volveremos más adelante sobre esta apreciación.)

Pero, ¿acaso hay que entender también la imbricación filosofía-historia en el sentido inverso, a saber, que no se puede hacer historia de las ideas sin partir de una detcrminada concepción filosófica tendencialmente intemporal (en el sentido, simplemente, de buscar situarse, como juez que rehúsa ser parte, fuera del objeto estudiado, el cual resulta indisociable de la temporalidad y la contingencia)?
A los que respondan negativamente a esta pregunta les lloverán sin duda los reproches de las diferentes escuelas analíticas, entre otras, que unirán por una vez $-y$ sin que siente precedente-sus voces a las de los neoescolásticos veneradores de una hipotética philosophia perennis. Uno, que no se considera analítico ni neoescolástico, se sumaría también con decisión al cacofónico coro si previamente pudiera dejar sentada la siguiente aclaración, de resonancias escolástico-empiristas: $n i-$ hil est in philosophia quod prius non fuerat in historia. Para añadir, por supuesto, inmediatamente, pero ya dentro del coro: nisi philosophtia ipsa.

En efecto -aunque una posición definitiva al respecto se precisará más adelante-, no parece que pueda haber ni siquiera doxografia sin un determinado punto de vista filosólico, por más que los grandes doxografos antiguos no rayaran a gran altura como filósofos -a excepción de Aristóteles, siempre y cuando se demuestre que el propio Aristóteles no bebio en la fuente de las Physikôn doxai de su discipulocompañero Teofrasto.

Cabe, por supuesto, la escapatoria del eclecticismo. Pcro ser ecléctico no es carecer de punto de vista filosofico, sino combinar puntos de vista filosóficos diferentes, seleccionar (ése es el significado etimológico de eklégein, de donde deriva 'ecléctico') conceptos filosóficos entresacados de diferentes sistemas o doctrinas para articularlos libremente en un ejercicio personal de interpretación no circunscrito a ninguna escuela determinada, Ejercicio, por cierto, que no es lícito condenar de antemano como no sea en aquellos casos en que los elementos conceptuales recombinados resulten incompatibles entre sí. De hecho puede decirse que la historia de la filosofia, en sus líneas más fecundas, es un proceso, no de 
creación ex novo, sino de sintesis innovadora de elementos preexistentes: la diferencia entre el malo y el buen eclecticismo radica en que este último opera con los elementos a modo de multiplicandos; aquél, en cambio, a modo de simples sumandos (que no pocas veces, además, se convierten en sustraendos).

Pero, sea ello como fuere, lo que aquí hace al caso es la idea de que no se puede explicar historia de la filosofía sino desde la filosofía, sea ésta una filosofía exclusivista o de escuela, sea una filosofia híbrida, ecléctica o, como seria preferible llamarla, «epistemológicamente tolerantes. Y ello es asi porque, si tiene razón Hegel al afirmar que la historia - sin adjetivos- no es la narración de un idiota (y creo que la tiene, por lo que luego veremos), con más razón hay que presuponer una lógica y un significado en esa parte de la historia que quiere ser a su vez, precisamente, la búsqueda de la lógica y el significado del todo en el que se inserta: historia de las ideas.

El dox6grafo puede parecer mejor historiador que el hermeneuta por la simple razón de que, en general, repite las ideas del autor comentado con las mismas palabras de éste. Pero la conciencia lingüística de la filosofía actual nos impide caer en la ilusión de creer que los mismos términos signilican las mismas cosas en contextos historicos diferentes (ilusión que explica, en último término, el enorme esfuerzo estéril de la Escolástica medieval con su pretensión de - dicho heideggerianamente- desvelar el Ser sin considerar el Tiempo). Repetir las mismas palabras, pues, no sólo no es garantía de fidelidad a las mismas ideas, sino más bien causa cierta de lo contrario: de la tergiversación de las ideas. El más grave anacronismo se da cuando, so pretexto de mantener los significantes, se alte- ran los significados y, por descontado, las referencias.

Los ejemplos históricos abundan. Por citar uno muy caro a los estudiosos del Doctor Angelicus, me referiré a la formulación de la famosa teoría tomista de la participación. Como es sabido, la definición que en dicha teoria se hace del ens, el ente, es: id quod habet esse, "aquello que tiene ser". A partir de dicha definición, y aplicando un recurso -éste sí- típicamente aristotélico, a saber, la transposición de una estructura sinfactica en estructura ontologica, Tomás de Aquino llega a establecer la nada aristotélica distinción entre esse y essentia, o existencia y esencia, distinción real y no meramente nominal ni de razón, que constituye lo que luego se llamaría "diferencia ontológica», base de la analogía de proporcionalidad por la que cada ente tiene en común con los demás el hecho de participar (literalmente: "tomar" o «tener parte») en el ser, ser único per se, por más que participado, y se diferencia de los otros entes en el hecho de poseer una esencia propia y exclusiva (si bien, en el caso de los entes materiales, el esquema se complica con una participación de segundo grado de los individuos, materialmente distin" tos, en una misma esencia o forma eidética común a todos ellos).

Pues bien, todo este entramado conceptual se sustenta en un colosal malentendido derivado de la errónea interpretación literal de la locución que ciertos comentaristas griegos de Aristóteles empleaban para designar el concepto de existencia. En efecto, el verbo griego einai, que en el período clásico bastaba para expresar la noción que nosotros cubrimos con el verbo 'existir' (más aún: tenía ésa como acepción principal, según se puede ver en la lógica de Aristóteles), se había desgastado de tal modo en la baja anti- 
güedad que, para expresar el sentido fuerte de 'ser' como existir, la koiné tardía hubo de recurrir a la perifrasis Echein einai, que sólo una visión mitificadora de las palabras como portadoras de "valores eternos" podía creer correcto traducir literalmente por habere esse («tener ser»), expresion que en latín, a diferencia del griego original, correspondía a una noción compleja en virtud de la cual la mera facticidad de la existencia (esse) quedaba objetivada y elevada gratuitamente a una dignidad conceptual que nunca tuvo en la doctrina aristotélica sobre el ente.

La doxografía, pues, al menos tal como se ha entendido desde Diogenes Laercio, bajo la apariencia de respeto fiel a la regla historiográfica según la cual ade ningún agente puede afirmarse definitivamente que haya dicho o hecho algo que nunca se le podría hacer aceptar como descripción correcta de lo que ha dicho o hechos, ${ }^{3}$ apariencia sustentada en el mantenimiento formal de un mismo vocabulario, oculta un entramado de sentidos y referencias diferentes que falsean por completo toda hipotética interpretación eliteral».

Claro que, según Richard Rorty, hay otra acepción menos cruda de 'doxografía”: aquella que puede aplicarse, en general, a todos los manuales de historia de la filosofía, y que el propio Rorty describe como «un intento tibio de contarnos una nueva historia del progreso intelectual describiendo todos los textos a la luz de descubrimientos recientes" 4 Rorty lo califica de intento "tibio" porque no afronta con suficiente decisión la tarea de modificar el "canon" o sistema vigente de valores historiograficos con arreglo al cual se adjudican rangos relativos $\mathrm{y}$ honores absolutos a las diversas figuras de la historia del pensamiento. En lugar de forzar esos cambios que hagan subir o bajar las respectivas "cotizaciones" de los valores filosóficos, el enfoque doxográfico se aviene a la componenda con los principales pretendientes a los puestos de privilegio. Eclecticismo de simple suma (o resta), que criticábamos antes, y que se sustenta en el presupuesto de que la filosofía es una «especie naturals, una esencia definible de una vez por todas (philosophia perennis) a cuyo paradigma ideal las diversas filosofias concretas se aproximan más o menos $\mathrm{y}$, en función de su proximidad, merecen ocupar un rango más o menos elevado en el cuadro de honor de la historia de las ideas.

En ninguna de estas dos acepciones parece admisible la doxografía. Hagamos tan solo la salvedad de que, aun siendo aplicable esa etiqueta, en uno u otro de los sentidos, a la práctica totalidad de los manuales de historia de la filosofia, ningún estudioso de ésta puede renunciar a su auxilio, a sabiendas de que es una muleta, pero precisamente por ello necesaria para paliar -no curar - la cojera inherente a cualquiera que desee tener visiones de conjunto siendo -como somos todos- incapaz de profundizar en algo más que unos cuantos hitos del dilatado curso histórico que desemboca en nuestro presente, Con ello estamos, por supuesto, justificando de paso la tarea de los «tibios" reformuladores de textos filosóficos pretéritos que son, en cuanto tales, los redactores de historias generales de las ideas. No es ningún desdoro para un especialista en Descartes tratar de ofrecer una panoramica global de los problemas planteados y las soluciones propuestas por todos aquellos a quienes considere interlocutores reales o potenciales del padre del racionalismo, filosofos en definitiva. Sólo que sus lectores habremos de tener la cautela de no admitir como obvio lo que él nos presente 
como tal y procurar reformular por nuestra cuenta - y riesgo- las formulaciones que nos proponga. A la «tibiezan de las formulas con que parafrasee los textos alejados de su campo específico habremos de oponer, alternativamente, el frío de nuestro escepticismo o el calor de nuestras propias ideas o intuiciones sobre el asunto.

Hecha esta salvedad consistente en salvar las no por deficientes inútiles historias de la filosofía al uso, hemos de dar la razón a Rorty cuando dice:

Para desembarazamos de esa idea de que la filosofía es una especic natural hacen falta, por un lado, más y mejores reconstrucciones históricas y, por otro, más Geistesgeschichte segura de sí. Debemos darnos cuenta de que las cuestiones que las «contingentes convenciones" de la época presente nos hacen ver como las cuestiones, son cuestiones que pueden ser mejores que las que nuestros predecesores se plantearon, pero que no necesitan ser las mismas. No son cuestiones con las que cualquier ser humano pensante necesarjamente se haya topado. Debemos vernos, no como respondiendo a los mismos estímulos a los que nuestros predecesores respondieron, sino como habiendo creado para nosotros mismos estímulos nuevos y más interesantes. Debiéramos justificarnos afirmando que formulamos mejores cuestiones, no afirmando que damos mejores respuestas a las "cuestiones profundas y fundamentales* permanentes a las que nuestros antepasados respondieron mal. ${ }^{5}$

Solo una cautela que añadir: nada garantiza que nuestros planteamientos, siendo en efecto distintos de los de filosofías anteriores, sean necesariamente mejores, como parece prestuponer Rorty dejándose llevar, quizá, por su a duras penas reprimida querencia analftica. (Sabido es que la tradición filosófica anglosajona, con la prepotencia que la caracteriza - revestida, eso sí, de irónica modestia- quisiera, en sus ma- nifestaciones más extremas, representadas por el positivismo lógico y la filosofía analítica, situar el libro del Génesis de su biblia filosófica en los escritos de Hume, el Exodo en Kant y, de ahí, saltar ya a un Nuevo Testamento inaugurado por el Evangelio de Frege.)

$Y$, sin embargo, en una cosa al menos tienen razón, siquiera formalmente, los filosofos analíticos: en su enfoque "reformulador" de las proposiciones filosoficas del pasado. Es el suyo un tipo de actuación historiográfica que a los ojos de un historiador epurom puede parecer espúrea y directamente ahistorica. Rorty la llama, con toda propiedad, "reconstrucción racional". Un ejemplo reciente entre nosotros lo constituye el estudio sobre la evolución de la racionalidad práctica emprendido por Antoni Domènech en su obra De la ética a la politica. ${ }^{6}$ El presupuesto de estos enfoques, que probablemente violan la regla de Skinner arriba citada (lo cual, en principio, no dice nada en pro ni en contra de su validez), podría enunciarse asi:

\section{Regla de reformulacion 1 (R.ref.I):}

Dado un conjunto $D$ de enunciados considerados mutuamente compatibles por su autor, es posible formular otro conjunto $D^{\prime}$ de enunciados que, conservando idéntica referencia $x$ que los primeros, exhiba ya en su misma forma logica dicha compatibilidad, $o$ bien admita un reordenamiento por el que unos enunciados sean deducibles de otros o de axiomas comunes no explicitados en $D$, o bien muestre contradicciones que hagan unos enunciados incompatibles con otros, refutando por tanto a $D$.

El punto débil de esta regla es, por supuesto, $x$, la referencia presuntamente idéntica a ambos discursos, para 
cuya determinación carecemos de criterios no intuitivos. Un planteamiento más cauto formularía esta regla casi al revés:

\section{Regla de reformulación 2 (R.ref.2):}

Supuesta una referencia $x$ para un conjunto $D$ de enunciados, siempre será posible elaborar un conjunto $D^{\prime}$ tal que, si denota con mayor univocidad que $D$ la supuesta referencia $x$ y exhibe una forma tal que permita apreciar un grado igual o mayor de consistencia entre los enunciados individuales 0 , por el contrario, revelar cualquier posible contradicción entre ellos, podamos concluir que $D^{x}$ es una reformulación adecuada de $D$ en el sentido de que confirma o invalida $x$ como su referencia.

De momento quede registrado asi nuestro juicio positivo sobre la legitimidad de lo que, en lenguaje más tradicional, deberiamos llamar actualizacion del pensamiento de otras épocas, y que, como hemos dejado sentado en R.ref.2, debe aceptar siempre un margen de indeterminacion respecto a la referencia de los enunciados "actualizados", una duda razonable sobre si con el nuevo lenguaje sobre un terra platónico, por ejemplo, estaremos realmente hablando de lo mismo que Platón. Si no es así, podremos sin embargo, como filosofos, encogernos de hombros y consolarnos diciendo aquello de que use non è vero, è ben trovatow: si la referencia atribuida al discurso reformulado no es la que realmente era, por lo menos habremos arrojado luz sobre una referencia interesante para nosotros y que, precisamente por resultarnos interesante, hemos creído descubrir en un texto del pasado. Como historiadores no podremos permitirnos tanta licencia, según veremos a continuacion; pero quizá lo que Platón se negaría a aceptar como idea suya (Skinner) le llegara a halagar como idea nuestra sobre él, con lo que "nuestro" Platón podría contar con la aquiescencia del Platón real aun sin identificarse con este. $Y$, en último término, "nuestro» Platón nos ayudaría a pensar a nosotros, cuya fidelidad a nosotros mismos es un valor superior a cualquier fidelidad historica.

Si R.ref.2 parece un criterio idóneo para hacer historia de la filosofia volcada al presente, no menos clara parece la validez de un procedimiento como el que ahora describiremos para hacer historia de la filosofía volcada al pasado. Me refiero a lo que Rorty llama «rcconstrucción histórica», y que consiste, no en la búsqueda de un nuevo lenguaje adaptado a nuestro contexto, como prescriben R.ref.I y R.ref.2, sino en la búsqueda exhaustiva del contexto al que se adapta el lenguaje original. Podriamos formularlo también en forma de regla, ésta sí compatible con la ya mencionada regla de Skinner:

\section{Regla de contextualizacion (R.con.):}

Dado un conjunto $D$ de enunciados, trataremos de hallar una referencia $x$ tal que haga compatible el sentido $S$ de $D$ con los sentidos $S_{i, .} S_{1 i}$ de los conjuntos de enunciados $D_{1 . . .} D_{n}$, cuyas referencias respectivas, $x_{k} \ldots x_{m}$, son ya conocidas.

Mientras que en el enfoque presidido por R.ref.l y R.ref.2 dábamos por supuesta una referencia para el discurso objeto y tratábamos, según el caso, de conservarla o confirmarla a través de otro discurso cuyo sentido se adaptara a nuestro propio contexto, en el nuevo enfoque historicista es precisamente esa referencia fontal la que bus- 
camos, la que constituye propiamente una $x$, una incógnita. En contraparti$\mathrm{da}$, el ejercicio de actualización renuncia a penetrar en el sentido propio del discurso objeto, mientras que el ejercicio historiográfico toma ese sentido como punto de partida y renuncia, en cambio, a dotar de nuevo sentido, mediante un discurso actual, a la referencia investigada. $\mathrm{Y}$ asf como R.ref.2 aceptaba un margen de indeterminación en $x$ pese a asignarle un valor dado hipotético (R.ref.1, que no lo acepta porque considera categórico el valor dado a $x$, sólo puede ser válida en casos en que $D$ tenga una referencia objetiva perfectamente contrastada, cosa altamente improbable en textos filosóficos), R.con. admite un cierto grado de indeterminación en $S$ pese a asignarle un valor dado hipotético.

La diferencia entre uno y otro tipo de indeterminación estriba en que el sentido, por definición (y como ya Hegel, antes que Frege, afirma, por ejemplo, en la primera página de su Introducción de 1823 a la Historia de la Filosofia), se agota por entero en la relacion de un discurso o fragmento discursivo con el todo o universo al que pertenece, en tanto que la referencia es el absoluto factual, inaprensible ciertamente fuera de todo entramado relacional, pero irreductible en si a su mera posición en dicho entramado, como sostén álimo que es de esa misma estructura, al modo como la materia, la hyle aristotélica, sustenta las configuraciones eidéticas que la informan y que, en definitiva, la manifiestan.

Por esa asimetría (que motiva, en último término, que en el enunciado de nuestras reglas metodológicas designemos la referencia con un símbolo de variable independiente, a diferencia de lo que hacemos con el sentido) es por lo que el enfoque reformulador y el contextualizador exhiben tan diferentes méritos cuando se los pasa por un mismo rasero epistemológico. Pero ello, lejos de ser un óbice, es un acicate para verlos como herramientas complementarias, igualmente indispensables en manos de un historiador de la filosofía. Porque ni un historiador puede resignarse a ignorar el sentido de un discurso del pasado y a dar por supuestas sin contrastación sus referencias, ni un filósofo puede avenirse a repetir discursos cuyo sentido es irrelevante para dar cuenta de las referencias que motivan su reflexión actual.

\section{Fitosofia en la historia, historia en la filosofía}

El historiador de la filosofía que no quiera contrariar a ninguna de sus dos "naturalezas" deberá, pues, aplicar alternativamente las dos reglas mencionadas. Ello le coloca sin duda, como "trabajador intelectual", en desventaja respecto de investigadores más unilaterales, como el simple historiador y el "simple» filósofo (las comillas son necesarias en este caso porque, como veremos, un filosofo no puede ser verdaderamente simple sin ser también simplista, atributo que supone una contradictio in adjecto). La desventaja estriba en que aquél tiene que realizar dos trabajos donde éstos sólo han de habérselas con uno: el doble cargo implica una doble carga.

No es que el historiador, por mucho que se ciña estrictamente a su labor de contextualización del pasado y de búsqueda de las referencias pretéritas ocultas a partir de las manifiestas, pueda librarse totalmente de los condicionamientos del presente: Ios conocimientos y las ideas vigentes en cada momento determinan qué es lo que aparece como manifiesto y qué lo que se adivina oculto $y$, a la vez, digno de ser 
investigado allá en el pretérito. Pero el historiador se limita a adoptar el enfoque que se desprende de esas ideas y conocimientos adquiridos sin interrogarse sobre su fundamento.

No es tampoco que el filosofo sin más pueda tratar de dar forma racional a sus preocupaciones sin servirse, en todo o en parte, de esta o aquella forma racional ya acuñada en el pasado para dar curso intersubjetivo a preocupaciones análogas (aunque nunca idénticas), porque el carácter secundario, indirecto, de las "referencias" del discurso filosófico las hace intrinsecamente dependientes (cuando no directamente derivadas) del sentido de discursos anteriores, lo que hace del filosofico un discurso csencialmente recurrente. Pero el filósofo sin más se desentiende de la adecuación o inadecuación de esas fomas racionales "prestadas" respecto a las preocupaciones pasadas que las originaron.

El historiador de la filosofía debe, pues - Wüde mit Bürde-, hacer ese doble trabajo, seguir las dos reglas arriba enunciadas. ¿En un orden determinado?

El buen juicio parece aconsejar que, antes de aplicar R.ref. 1 o R.ref.2, empecemos tratando de determinar con certeza el valor de $x$, la referencia del discurso filosófico estudiado, cosa que sólo lograremos aplicando R.con.

Ahora bien, ¿qué es lo que determina, como en el caso del simple historiador, la elección de tal o cual $x$ como incógnita cuyo despeje resulte interesante? Los conocimientos, ideas y "prejuicios» adquiridos, vigentes en cada momento en la mente del historiador de la filosofía. Pero éste, a diferencia del historiador no doblado de filósofo, tiene como divisa resistirse a aceptar y aplicar ciegamente esquemas preconcebidos (por más que hoy abunde tanto el intrusismo de los adictos al filosofema prêt à penser, de quienes no cabe tanto criticar su falta de profesionalismo como su exceso de éste). Ese prurito criticista, definitorio del filósofo frente a otros productores de ideas, impide prescribir a la historiografía filosófica una suerte de regla de reglas que consista en imponer a éstas una ordenación del tipo:

\section{Si R.con.,(D), entonces y sólo entonces R.ref.(D)}

$¿$ Quiere eso decir que hay que invertir el orden y subordinar la regla de contextualización a la regla de reformulación, tratando previamente de dar sentido actual al discurso cuya referencia nos parece afín a nuestros intereses, para tratar luego de confirmar o descartar esa afinidad? Si lo hacemos así, perderemos fácilmente de vista la urdimbre histórica real, pues iremos saltando de aquí para allá en el tiempo, seducidos por las apariencias de afinidad referencial que nos ofrezcan tales o cuales discursos del pasado, sin conexión directa entre sí.

¿Nos hallamos, pues, como Ulises, ante una Escila y Caribdis epistemológica? Si. Y ésa es la causa de que en los anales de la navegación históricofilosófica se cuenten por bastante más que docenas los naufragios. Más aún: quizá haya que decir que la historia de esa navegación es la historia de un naufragio, como en último término viene a decirnos Rorty.

Pero, si es así, habrá que concluir que se trata de un naufragio necesario y que el arte de navegar por esas aguas es cl arte de naufragar. No naufragan, por supuesto, quienes desisten de la travesía y se quedan firmemente anclados en uno u otro puerto, como puros historiadores o como filosofos "sincronicistas" (y la mayor parte de las escuelas contemporáneas, empezando por el neopositivismo y la filo- 
soffa analitica, siguiendo con el estructuralismo y acabando en el textualismo desconstruccionista, propenden a la más estricta - y estrecha- sincronía).

Los que acepten, en cambio, esa vision trágica del pensamiento que propugna Eugenio Trías y se aventuren rumbo al seguro naufragio podrán consolarse con la idea romantico-hegeliana (también schilleriana) de la superacion (Aufhebung), tan mal comprendida por los sincronicistas de todos los tiempos. Esa paradojica síntesis de supresión-conservación que define a la Aufhebung se zafa de las cadenas del irrefutable principio de no contradicción por la dimensión extralógica de la temporalidad, abstracción cuyo correlato concreto es precísamente la historicidad (quizá habría que decir incluso que, justamente porque la ley objetiva que expresamos con el principio de no contradicción impide que un mismo sujeto reciba y no reciba un mismo atributo al mismo tiempo, por eso mismo los sujetos existen en el tiempo: para poder desplegar a lo largo de el todo su significado; significado que, como señala Wittgenstein, adquiere su plenitud en la contradicción y se reduce a nada en Ia tautologia).

El historiador de la filosofía, por consiguiente, naufraga porque es imposible recuperar en un discurso con sentido actual la realidad en cuanto enunciada por otro discurso cuyo sentido ha dejado - supresión- de ser actual ('actual' = 'contextualizable en el universo discursivo vigente'). Pero no puede dejar de navegar hacia el naufragio porque, en cuanto filosofo historiador, reconoce que ningún discurso actual tiene sentido si se corta el cordón umbilical (la "sagrada cadena", diria Herder) que lo une -conservacion- a los discursos del pasado, cuya problematicidad irresuelta es justo el desencadenante de nuestros intentos de solución presentes.

Precisamente porque la filosofía de hoy contiene, reducida a cuadro sincrónico, una historia de respuestas insatisfactorias que han provocado $y$ prestado sus términos a la pregunta de hoy, por eso precisamente la historia contiene entre sus desarrollos tambien un desarrollo filosófico, un flujo diacrónico de preguntas. Y viceversa. Circularidad aparente que oculta, a los ojos miopes del sincronicista, un avance real en el que nunca se regresa al punto de partida: vamos constantemente de Escila a Caribdis y a la inversa, pero avanzamos porque Escila $y$ Caribdis no son meras ideas persistentes en la abstracción, sino manifestaciones concretas de una realidad que materialmente no es nunca la misma.

Esta conciencia de la condición del filosofo historiador encuentra cumplida expresión en Hegel, para quien la filosofía es el producto del pensamiento que trata de producirse a si mismo; autoproducción que es en realidad un Entdeckungsreise, un aviaje de exploración que el pensamiento emprende para descubrirse a sí mismo", ${ }^{7}$

Si a esa exposición le rebajamos el optimismo idealista que la lleva a cxagerar el aspecto autocreativo del pensamiento, tendremos una pintura bastante aproximada del diacronismo intermamente generado que es preciso reconocer en la reflexión filosófica. Hegel $_{\text {s }}$ por supuesto, no habla de "naufragion; pero admite que ese viaje de exploración es "milenario" (lo que es tanto como admitir que ninguno de los barcos fletados hasta ahora por el pensamiento - los sucesivos filosofos individuales- ha arribado nunca a puerto). Por otro lado, tampoco la del naufragio es una metáfora que pueda tomarse al pie de la letra o en sentido absoluto: mientras subsista la especie 
humana y no se precipite en la barbarie insensibilizadora (distinta, por cierto, de la recaída en el salvajismo primitivo, como señala agudamente Schiller), en los sucesivos naufragios quedara siempre un superviviente: la voluntad, contra viento y marea, de seguir filosofando.

Hegel expresa también de otra manera esa tarea inacabable (no porque haya, como Sísifo, que volver continuamente a subir la misma montaña, sino porque a cada momento se descubre que la montaña es más alta de lo que parecía): dice, en efecto, que, asf como la religión afirma una verdad inconmovible y consagrada de una vez por todas, $\mathrm{y}$ las ciencias particulares acumulan sucesivos conocimientos que, salvo en contadas ocasiones (lo que hoy llamarfamos "revoluciones cientificas"), no suponen una alteración o modificación de los ya adquiridos, sino la simple adición o incorporación de los nuevos a los viejos, la filosofía, en cambio, es «el espectáculo de unas alteraciones constantes dentro del todo». En efecto, el espiritu, cuya historia constituye la filosofía, es acción; y la accion se ejerce, sobre la materia que es su objeto, no mediante simples aumentos o reducciones cuantitativos, sino mediante transformaciones cualitativas. ${ }^{8}$

Esa constante creación de sentidos nuevos, motivada, paradójicamente, por el intento de comprender el sentido de lo ya creado con anterioridad, es lo que Rorty llama, rindiendo el merecido tributo a Hegel, Geistesgeschichte, "historia del espiritu". Y ése es el modelo historiográfico que la filosofía reclama para si. Modelo cuya referencia es el pensamiento de la realidad en el acto de crearse a sí mismo al recrear a esta; acto que, para consumarse, ha de recrear en cada nueva fase todas sus creaciones anteriores, porque sin reno- var la conciencia de éstas perdería por un extremo lo que ganara por el otro (y éste no es un postulado idealista, sino todo lo contrario: la pura idea estarra, como tal, siempre presente a sí misma, mientras que la necesidad de actualizarse es propia de un pensamiento que tiende a perderse constantemente en la materia de la que aflora).

Modelo, pues, que integra la reformulación y la contextualización en un movimiento alternativo de la una a la otra en el que la una y la otra van colmando sus vacios respectivos a la vez que abren nuevos vacíos de un orden superior. Singladuras siempre nuevas y nunca definitivas que, desde la exigencia de saber absoluto al que la filosofia -ilusoria pero no ilegitimamente-aspira, no pueden por menos de considerarse naufragios reiterados pero nunca definitivos.

Pero si la filosofía no puede separarse de $s u$ historia es, en último término, porque no puede separarse de la historia. Nada hay en la historia que la filosofía deba considerar ajeno. El ápice de intemporalidad que caracteriza al filosofar como búsqueda de una verdad que no por histórica puede nunca dejar de ser verdad en su lugar y tiempo es justamente lo que le permite penetrar en cualquier época y circunstancia.

Tiene, pues, razón Alain Badiou cuando dice (Manifeste pour la philosophie, París, Seuil, 1989) que la filosofia requiere unas condiciones minimas que no siempre se han dado ni tienen por qué seguir dándose en el futuro: no todo lo que esta en la historia es filosofía. Pero, en cambio, no tiene razón cuando dice, con otras palabras, que no todo lo que es historia puede estar en la filosofía.

Por supuesto, al sostener esto se viene a suscribir, como ya se anuncio, el 
lema hegeliano: "todo to real es racionals. Solo al confundir esta pura afirmación de hecho con un juicio de valor (atodo lo que es, es como debe ser»), o al convertir el predicado racional' de categorico en apodíctico ("todo lo que es, tenía necesariamente que ser as(w), ha podido verse en ese lema un exceso idealista. Si todo lo real no fuera pensable y explicable (adjetivo, este último, no sinónimo de 'justificable'), nadie podría sostener siquiera que tal o cual cosa es irracional, distinguiéndola así, siquiera implicitamente, de otras que no lo son. En efecto, esa distinción presupone una relación; ahora bien, la racionalidad es, por definición, sinónimo de relacionabilidad o conmensurabilidad. Así, de la raíz cuadrada de 2 se dice que es "irracional» no en sentido absoluto sino, etimológicamente, porque expresa el valor de la diagonal de un cuadrado a cuyo lado se ha asignado el valor $1, y$ ambas magnitudes resultan inconmensurables, es decir, no mensurables con el mismo patrón de medida por el cual consideramos a una de ellas como unidad; pero, por supuesto, tanto la diagonal como el lado son perfectamente mensurables cada uno con arreglo a una $u$ otra escala y perfectamente conjugables, pensables conjuntamente dentro de una relación geométríca precisa. La irracionalidad se manifiesta, pues, como imposibilidad de relacionar entre sí determinadas realidades con arreglo a determinados patrones, nunca como imposibilidad de cstablecer tipo alguno de relación.

De modo que ni siquiera lo que hemos llamado metaforicamente unaufragion histórico-filosofico es un absurdo inexplicable, carente de sentido, irracional en suma. Es, en cambio, el resultado necesario y perfectamente anticipable de unas determinadas constricciones: constricciones de una realidad natural que se diluye en el tiempo y de una conciencia que solo escapa a esa disolución creando para si artificios intemporales que son, por cllo mismo, modelos desnaturalizados de aquella realidad.

La racionalidad de lo real es el presupuesto básico de toda filosoffa, su condición de posibilidad (tanto si la filosoffa de que se trate en cada caso lo reconoce como si no). Las constricciones recién mencionadas son, a su vez, la causa de su historicidad como filosofias. Los excesos logicistas y finalistas de la interpretación de aquel lema por Hegel no constituyen base alguna para su refutación, de la misma manera que la falsación de la teoría aristotélica de los lugares naturales no refuta la carda de los cuerpos. El lema es válido y la filosofía, por tanto, posible, a condición, simplemente, de reconocer la materialidad y la temporalidad, no como dimensiones extrarracionales, sino como los "contornos" propios de la racionalidad, como los límites inmanentes necesarios para su constitucion como racionalidad de algo. Esos límites impiden que la razón le imponga una finalidad a la historia. Pero su inmanencia impide asimismo que la historia le imponga un final a la filosofía. Como dice Badiou, «concederíamos una inmerecida victoria a Hitler y a sus esbirros si así, por las buenas, los declaráramos capaces de haber introducido lo impensable en el pensamiento, de haber logrado el cese de su ejercicio estructuradon."

\section{Conclusión: idea, realidad y praxis}

Como vimos más arriba, la filosofía es para Hegel el (sub)producto resultante de la autoproducción del pensamiento. De forma menos paradójica e inmodesta lo expresa Antonio Gramsci al decir que las ideas no son reflejos in- 
mediatos de la realidad, sino que están mediadas por la práctica; que no son tanto representaciones del ser como autopresentaciones del hacer.

Este enfoque epistemologico no teoreticista, que hace pasar el vinculo entre el cerebro y los objetos a través de la mano, es también el de Charles Taylor, y en él justifica la necesidad que la filosofía tiene de la historia:

Asi, para entendernos a nosotros mismos en el presente nos vemos llevados al pasado en busca de las afirnaciones paradigmáticas de nuestras explicitaciones formativas. Nos vemos forzados a retroceder hasta el descubrimiento pleno de aquello en lo que hemos estado, o en lo que nuestras practicas fueron forjadas. [...] esta necesidad puede surgir como resultado de un cambio o de un desarrollo. Pero también puede surgir en razón del modo en que las explicitaciones pueden distorsionar $u$ ocultar en parte lo que esta implícito en las prácticas. ${ }^{10}$

Éste es también, en definitiva, el enfoque que aquí se defiende. Enfoque que ve las ideas más como productos que como reflejos, verum factum (Vico). Enfoque que sólo justifica el reconocimiento a Platón de los derechos de patente sobre la filosofía en la medida en que Platón fue el primero en derivar una teoría sobre el mundo y el hombre a partir de una experiencia $y$ un proyecto de organización social. El primero en subordinar toda idea universal abstracta a la idea universal concreta de fin práctico: la idea de Bien.

Ver el pensar como producción interiorizada permite superar la antinomia lenguaje-pensamiento que, mal resuelta a favor del primero, ha acabado generando ese formidable equívoco que llamamos textualismo o desconstruccionismo y que constituye la -por hoy- postrera forma conocida de es- cepticismo nominalista. La reducción de los conceptos a estructuras lingüísticas es legítima si y sólo si, como Tarski y Davidson, reconocemos en el fondo de todo sentido una referencia. Ahora bien, esta última deja de resultarnos inasible y paradojicamente extralingǘstica como la kantiana «cosa en sìs sólo cuando la situamos, no en el mundo de las cosas, sino en el mundo de los actos, del que también forma parte el lenguaje.

Este enfoque, que en lo esencial - como pone de manifiesto Charles Taylor - es un ejercicio crítico con las ideas recibidas, reconoce no obstante, con Epicuro, la necesidad para toda filosofia de un momento dogmático o de autoafirmación, pues es imposible criticar sin creer, al menos; en la propia crítica. Pero es a la vez un enfoque con la suficiente dosis de tolerancia (derivada del reconocimiento de que ninguna idea carece por completo de sentido, pues todas proceden en último término de alguna experiencia práctica real) como para entreverar las propias afirmaciones con repliegues de sano escepticismo, fundamento último de una "República de las Ideas" democrática y pluralista.

El estudioso de la filosofía que se deje persuadir por este planteamiento de su historia, aun siendo consciente de que es imposible conocer el pasado en cuanto tal, encontrará en su comprensión de las ideas del presente, no sólo toda la densidad acumulada en ellas por las ideas producidas en el pretérito, sino todo el espacio de posibilidades que esas ideas abrieron y que hoy está sin ocupar, envolviendo nuestra práctica real como el vacío envuelve los cuerpos y determinando, en toda su relatividad, la posicion que hoy ocupa nuestro pensamiento. 


\section{NOTAS}

1. Alasdair Macintyre, *La relación de la filosofia con su pasadon, en R. Rorty et al, La flosofia ent la historia. Barcelona, Paidós Ibérica, 1990, p. 49.

2. Problemas y nétodos de la investigación en historia de la filosofia. Tucumán, $1949, \mathrm{pp} .28$ y ss.

3. $Q$. Skinner, aMeaning and understanding in the history of ideass, History and Theory, 8 (1969), 3-53.

4. x.a historiografía de la fllosofía, en $R$. Rorty et al. op. cit, p, 84.
5. Tbid. , p, 85 .

6. Barcelona, Critica, 1989.

7. Op. cit. p. 2

8. Introducción de 1816 a la Historia de la Filosofia, pp. 17 y 14 de la ed. de J. Hoffmeister, Famburgo, F. Meiner, 1966.

9. Op. cit, p. 11.

10. C. Taylor, a fa filosofia y su historias, en R. 